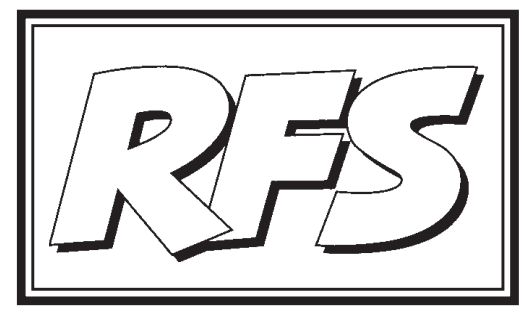

Revista de Fomento Social, 59 (2004), 13-38

\title{
Financiación autonómica: Un reto para el nuevo gobierno
}

\author{
(Palabras clave: Financiación autonómica, Sistema Foral, Autonomía, Solidaridad. \\ KEY WORds: Regional Financing, Autonomous financing, Autonomy, Solidarity)
}

\section{Introducción}

En este artículo editorial queremos abordar un tema actual, técnicamente complejo pero esencialmente político, y, al mismo tiempo, de un hondo contenido ético, que esperamos hacer explícito en las páginas que siguen. Nuestra decisión de volver sobre este tema, del que ya nos hemos ocupado hace unos $a_{n}{ }^{2}{ }^{2}$, surgió a mediados de diciembre de 2003, cuando el gobierno de Cata-

1 Para esta reflexión hemos contado con la ayuda especial de nuestra colega la Profesora Araceli de los Ríos Berjillos, a quien agradecemos su valiosa colaboración.

2 Como recordarán nuestros lectores, ya nos ocupamos de esta cuestión en nuestro editorial: "La solidaridad interterritorial en cuestión", Revista Fomento Social nํ 213 (enero-marzo 1999). 
luña presentó su proyecto que recogía muchas propuestas de reforma de la financiación de esta comunidad autónoma. Este fue el factor detonante que otras comunidades, como Andalucía, aprovecharon, para plantear sus propias aspiraciones.

La respuesta de los principales partidos políticos fue muy diferente. El Partido Popularno incorporó a su programa electoral para el 14 de marzo la modificación de la financiación autonómica. En realidad, el gobierno del PP había aprobado en 2001, en consenso con los distintos gobiernos autonómicos, el último sistema de financiación, que se consideró en aquel momento como definitivo y que se viene aplicando desde 2002. Para el PP, además, las propuestas del tripartito catalán fueron consideradas un ataque a la unidad del Estado. La reacción del PSOE fue diferente: entendía que aún existía margen para modificar la financiación autonómica y dar respuesta a algunas de las propuestas del gobierno catalán y del andaluz. Por eso uno de los puntos de su programa electoral fue la modificación del sistema de financiación autonómica.

A la vista de los resultados de las elecciones del 14 de marzo, este editorial, cuyo contenido estaba muy avanzado ya para esa fecha, adquiere mayor actualidad. En efecto, el triunfo del PSOE hace suponer que en los próximos años habrá algunos cambios al respecto.

Nuestro objetivo no es sólo arrojar luz sobre las principales propuestas que se han realizado, valorando sus aspectos técnicos y también los principios o valores implícitos en cada una de ellas. Pretendemos ir más allá, poniendo de manifiesto el problema de fondo. Porque ¿no es sorprendente que a los dos años del funcionamiento de un sistema de financiación autonómico que se presuponía definitivo, ya se esté proponiendo su modificación? El lector no experto en el tema puede achacar dichas propuestas a los cambios de gobierno y a los enfrentamientos entre gobierno central y gobiernos autonómicos, a los que nos ha habituado la marcha política del país. Esta conclusión, sin ser del todo inexacta, no tendría en cuenta, sin embargo, el alcance del problema que aquí subyace: los dos diferentes sistemas de financiación autonómica que existen en España, el de las comunidades forales y el de las CCAA de régimen común. El sistema de financiación foral aporta una mayor autonomía financiera al País Vasco y a Navarra, un privilegio de estas dos comunidades forales que tiene un origen histórico y que está reconocido en la Constitución (Disposición adicional $1^{\underline{a}}$ ). Aunque el sistema de financiación general (de régimen común) ha ido aproximándose al foral, aún está lejos de él. Algunas CCAA no se resignan a ello y, por eso, aspiran a conseguir un sistema similar. 
Porconsiguiente, la financiación de las autonomías es la "punta de un iceberg" de una masa compacta de cuestiones de mayor calado, a veces explícitas y otras veces no. Esta complejidad nos va a obligar a realizar ciertas incursiones para abordar con rigor cuestiones de diversa índole y naturaleza. Entre ellas: valores compartidos por la sociedad y puestos en juego, como son la solidaridad, la subsidiariedad y la igualdad; razones históricas que explican y fundamentan (¿desde cierto anacronismo?) la legitimación de algunos privilegios; razones políticas y partidistas que explican el interés "no sólo racional" de algunas medidas; cuestiones técnicas (administrativas, contables o tributarias) que condicionan la viabilidad de ciertas propuestas; cuestiones económicas (entre las que los problemas de asignación eficiente son esenciales).

Todo este conjunto de cuestiones se mezclan en un debate que aparentemente adopta una estructura racional de toma de decisiones: análisis del problema, elaboración de alternativas por los participantes, evaluación y propuesta de solución. Sin embargo, los intereses puestos en juego cuando se habla de financiación autonómica ejemplifican lo que la literatura organizativa denomina "proceso cubo de basura": ante una situación dada, los problemas, las alternativas, los participantes y las soluciones coexisten de manera independiente; de este modo, las soluciones buscan problemas y participantes (en lugar de lo contrario) y, en consecuencia, los problemas siguen sin resolverse, o a lo sumo se resuelven parcial o coyunturalmente, ya que las conexiones entre problema y solución son "artificiales" $y$ "oportunistas".

Con la intención de clarificar todo lo anterior, el editorial se ha estructurado en tres partes. En primer lugar expondremos los presupuestos de partida en la financiación autonómica: dichos presupuestos se refieren a los principios o valores que deben inspirar todo sistema de financiación regional (teniendo en cuenta nuestra Constitución y nuestra propia tradición), y no son independientes de cómo se organizan territorialmente los Estados, ni de ciertas circunstancias históricas que condicionan nuestro modelo autonómico (pero que no podremos abordar aquí con el detalle que merecerían). En segundo lugar discutiremos la parte de razón que llevan tanto las comunidades forales como las CCAA de régimen común, analizando las diferencias que existen entre la financiación de unas y otras. Finalmente estudiaremos las propuestas recientes de algunas comunidades de régimen común con el objetivo de aproximarse al sistema foral. Esta última parte se adentra en consideraciones quizás demasiado técnicas, pero lo hacemos para mostrar que detrás de ellas, no sólo hay cuestiones técnicas, sino también valores en juego, como son la solidaridad interpersonal e interterritorial. 


\section{Los presupuestos de partida en la financiación autonómica}

\subsection{Los principios}

Todo problema económico y, por tanto, de asignación de recursos escasos (los medios financieros) a fines alternativos (financiación regional, central o local) requiere aplicar un criterio de decisión, detrás del cual existen unos valores o principios. En nuestro caso, y con el fin de que tanto las CCAA como las corporaciones locales dispongan de recursos suficientes para sus gastos, estos valores o principios son: suficiencia, autonomía financiera, solidaridad y coordinación. El sentido y alcance de cada uno de estos principios puede sintetizarse como sigue.

- La suficiencia implica dotar a cada nivel de gobierno de los recursos financieros necesarios para responder adecuadamente a las competencias que tiene asignadas.

- La autonomía financiera (Constitución Española, art. 156) supone dotara cada nivel de gobierno de la capacidad para legislar sobre sus impuestos y para aumentaro disminuir los recursos financieros, adecuando así el nivel de prestación de los servicios públicos a la demanda de los ciudadanos de cada región o localidad ${ }^{3}$. La eficiencia con que cada nivel de gobierno presta sus respectivas competencias depende, a su vez, de un concepto que está directamente relacionado conél: el de corresponsabilidad fiscal. Existe corresponsabilidad cuando el responsable del gasto es también responsable de recaudar y el ciudadano percibe el coste de los servicios que recibe del sector público, por lo que su demanda es más racional y, por tanto, el gasto público es más eficiente.

- La solidaridad financiera (Constitución Española, arts. 138, 156, 158) implica redistribuir los recursos con una doble finalidad. En primer lugar, reducir las desigualdades interterritoriales, objetivo este más amplio de lo que la financiación de los gobiernos subcentrales puede abarcar ${ }^{4}$. En

3 Para que exista autonomía financiera es fundamental que haya capacidad normativa. Esta puede ser propia, capacidad para que los gobiernos autonómicos creen sus propios tributos, o cedida por el Estado, que sería la capacidad para modificar algún o algunos parámetros de los tributos de normativa estatal, con la finalidad de aumentar o reducir la recaudación.

4 Por esta razón una política redistributiva ha de ser, en última instancia, competencia del gobierno central. 
segundo lugar, nivelar la prestación de servicios, garantizando a los ciudadanos un nivel relativamente homogéneo de servicios, con independiencia de su lugar de residencia. Si no existiera este mecanismo redistributivo, habría regiones que, con el mismo esfuerzo fiscal, podrían ofrecer a sus ciudadanos una mejor prestación de los servicios públicos que otras; o, lo que es lo mismo, habría regiones que tendrían que aumentar los impuestos a sus ciudadanos para que estos tuvieran unos servicios similares a los de otras regiones.

- La coordinación (Constitución Española, arts. 103, 156) es necesaria en la medida en que las competencias sobre los ingresos y gastos públicos se comparten entre los gobiernos central, autonómicos y locales. Mediante la coordinación se persigue una mayor eficiencia en la gestión de los ingresos y gastos públicos, evitando las "ineficacias de escala"; pero también se pueden conseguir con ella efectos multiplicadores positivos en las regiones más desfavorecidas (es lo que ocurre, por ejemplo, al coordinar los Fondos de la Unión Europea con la política de inversiones del gobierno de un Estado miembro).

Para dimensionar mejor el alcance de todos estos principios conviene añadir la exigencia de eficiencia global del sistema de financiación pública. En realidad no es tanto un principio para la financiación autonómica cuanto un criterio que afecta al conjunto del Estado. Pero es esencial para evitar el peligro de que "los árboles nos impidan ver el bosque".

\subsection{Las dificultades en la aplicación de estos principios}

Todos los principios enumerados han de tener una presencia efectiva en cualquier sistema de financiación, ya sea central, autonómico o local. Nuestra Constitución no otorga un papel predominante a ninguno de ellos: cabe deducir que todos son considerados de igual importancia. El problema surge porque hay cierta incompatibilidad entre algunos de estos principios, en concreto, entre la autonomía financiera y la solidaridad. Veamos por qué.

Si el sistema de financiación autonómica dotara a las regiones de autonomía, pero no existiera solidaridad, en el sentido de redistribución de recursos para nivelar el gasto, eso llevaría al incumplimiento de otro principio, el de igualdad en el nivel de acceso y prestación de los servicios públicos de los ciudadanos en todo el territorio nacional (equidad, cf. Constitución española, arts. 14, 31-2, 138-1, 138-2, 139, 158). Como ya se ha indicado, las características socioeco- 
nómicas de las regiones españolas determinan que, para un mismo esfuerzo fiscal, haya comunidades que puedan ofrecer un mayor nivel de servicios que otras. La autonomía financiera de las regiones puede provocar tensiones con el principio de igualdad o equidad, las cuales deberían ser compensadas por la actuación del Estado en virtud del principio de solidaridad.

Situémonos en el extremo contrario, el de un sistema de financiación regional que no dotara de autonomía financiera a las regiones. Entonces el responsable del gasto, el gobierno regional, no sería, a su vez, el responsable del ingreso, por lo que podría trasladar a la Administración central la responsabilidad sobre el gasto, es decir, sobre la prestación de servicios en la región. Además, el ciudadano no percibiría cuánto cuestan dichos servicios, por lo que la demanda sería menos racional. Efecto de todo ello sería el sobredimensionamiento del gasto, no sólo por la mayor demanda de los ciudadanos, sino también porque quien gasta no tiene la responsabilidad de recaudar.

Por tanto, en cualquier sistema de financiación regional debe existir un equilibrio entre la autonomía y la solidaridad del sistema. Pero no es fácil determinar el punto de ese equilibrio y cómo llegar a él por una vía de consenso.

En la práctica, todas las CCAA han mostrado en la última década su deseo de avanzar en la autonomía del sistema de financiación autonómica, pero con una diferencia: las regiones con menor nivel de desarrollo socioeconómico han intentado que este proceso se produjera sin renunciar a la solidaridad del sistema, mientras que las regiones de mayor desarrollo han defendido, en algunas ocasiones, posturas contrarias a la solidaridad o, al menos, en las que este principio estaba ausente.

Es difícil determinar con exactitud cómo conjugar autonomía y solidaridad en el sistema de financiación regional. Permítasenos aportar, al menos, algunas ideas y mostrar los vínculos de esta cuestión con el modelo de Estado subyacente.

La Constitución dota a las CCAA de autonomía para financiar las competencias transferidas (art. $156^{5}$ ). La autonomía no es la apropiación de todos los recursos generados en un territorio. Esta apropiación tiene un doble límite. En primer lugar, se limitaría a los recursos necesarios para financiar las competencias transferidas al nivel deseado (demandado) por los residentes

5 "Las Comunidades Autónomas gozarán de autonomía financiera para el desarrollo y ejecución de sus competencias con arreglo a los principios de coordinación con la Hacienda estatal y de solidaridad entre todos los españoles". 
de la región; ello requiere, como ya hemos indicado, la capacidad de dictar normas sobre la estructura de sus tributos. Pero existe un segundo límite, más sutil sin duda: que el ejercicio de la autonomía no conduzca a la obtención de "ganancias fiscales". En efecto, en algunas CCAA (por ejemplo, Madrid) los recursos generados superan las necesidades de financiación, mientras que en otras (como Extremadura) dichos recursos no alcanzarían para financiar el coste de los servicios que tiene transferidos. Por tanto, existe un criterio para la apropiación de recursos tributarios generados en un territorio por parte del gobierno regional; el gasto total a financiar.

Es evidente que, dada la realidad socioeconómica de las regiones españolas, el grado de autonomía financiera que puede alcanzar cada región es distinto. Pero esto no implica que el sistema sea insolidario: sólo sería insolidario si no existieran mecanismos redistributivos que compensaran dichas diferencias.

Ahora bien, detrás de este límite en la aplicación del principio de autonomía (la financiación del gasto transferido) existe una idea de Estado. A diferencia de lo que ocurre en un Estado unitario descentralizado (y nuestro actual Estado de las autonomías tiene ahí su origen), la transferencia de competencias en un Estado federal -y, por lo general, también de recursos-se efectúa desde las regiones al gobierno federal o confederal. Es decir, el proceso arranca de unos Estados inicialmente independientes que ceden competencias a un nivel de gobierno superior o federal. Esta diferencia es importante, y afecta tanto al principio de autonomía como al de solidaridad.

Respecto al principio de solidaridad, en un Estado federal las diferencias entre los distintos Estados son consecuencia directa de la gestión que ha realizado cada uno de los diferentes Estados; esto no es incompatible con que, al constituirse como Estado federal, traten de reducir dichas diferencias interestatales, pero parece lógico que esas diferencias se acepten sin que se presten a agravios comparativos. Sin embargo, cuando un Estado unitario se descentraliza es más difícil aceptar las diferencias entre regiones, porque parece lógico esperar que en el momento del traspaso la prestación de los servicios públicos en todo el territorio nacional fuese similar, al ser un único Estado el responsable de dicha prestación. Pero esto no ocurría en España en el momento de la creación del Estado de las autonomías. Nuestra Constitución se refiere al principio de solidaridad en el artículo $138^{6}$.

6 “1. El Estado garantiza la realización efectiva del principio de solidaridad, consagrado en el artículo 2 de la Constitución, velando por el establecimiento de un equilibrio económico, 
Admitiendo que la solidaridad es un principio que debe estar presente en cualquier Estado, independientemente de su organización territorial (unitaria descentralizada o federal), lo anterior nos lleva a afirmar que el grado de solidaridad debe ser mayor en un Estado unitario descentralizado, cuando no ha cumplido la premisa de que, en el momento de la descentralización, el nivel de prestación de los servicios fuese similar en todo el territorio nacional.

Respecto a la autonomía financiera, en la confederación de Estados, la titularidad de los recursos tributarios es originariamente de cada uno de los Estados, los cuales cederían parte de dichos recursos a la confederación para financiar el gasto común: en este caso, la transferencia de competencias es desde las regiones a la confederación, o desde los gobiernos regionales a un gobierno federal y, por tanto, la aportación de recursos debe estar limitada al volumen de gasto federal o confederal a financiar. Pero este no es el caso de nuestras CCAA: estas no pueden reclamar la apropiación de todos los recursos generados en su territorio, porque es este nivel de gobierno el que ha recibido el traspaso de competencias, cuya titularidad era inicialmente del Estado, igual que lo es la de los recursos tributarios. Es decir, cuando los Estados se unen, "ceden" para financiar los gastos comunes; cuando un Estado se descentraliza, el "dueño" es el que cede.

De todo lo anterior se puede sacar una conclusión: cuando algunas CCAA reivindican la recaudación de todos los recursos generados en su territorio, a través de la autonomía financiera, están exigiendo una mayor autonomía política y, al mismo tiempo, están cuestionando la organización actual del Estado español. Pero esto ya plantea problemas de índole constitucional (art. 14) e incluso condenaría a una cierta recesión a algunos territorios del país. ¿No es esto tensar demasiado la cuerda?

No queremos decir que nuestra Constitución sea inamovible y no excluimos que, en algún momento, se pueda proponer su reforma en lo que a la organización territorial del Estado se refiere. Ahora bien, tanto si España sigue siendo un Estado unitario descentralizado como si se organiza como un Estado federal, habrá que seguir dando una solución al problema de conciliar la autonomía de las regiones o Estados con la igualdad de derechos y deberes que corresponden a todos los ciudadanos por el hecho de pertenecer a un mismo Estado.

adecuado y justo, entre las diversas partes del territorio español, y atendiendo en particular a las circunstancias del hecho insular.

2. Las diferencias entre los Estatutos de las distintas Comunidades Autónomas no podrán implicar, en ningún caso, privilegios económicos o sociales." 


\section{Financiación foral y financiación de régimen común: diferencias}

Cuando en 2001 se aprobaba el actual sistema de financiación de las CCAA de régimen común, y se destacaba que era un sistema definitivo, algunos ya nos cuestionábamos que eso fuera a ser realmente así. La razón es que, a pesar de ser un buen sistema, que responde a las principales demandas de las CCAA (cesión del rendimiento de los impuestos indirectos, incorporación de la sanidad al sistema de financiación, actualización de la variable población, establecimiento de las asignaciones de nivelación, etc.), sigue siendo un sistema que aporta menos autonomía financiera que el sistema foral.

Las diferencias entre un sistema y otro no son banales. Por eso es preciso que nos detengamos en este momento de nuestras reflexiones para tomar conciencia de ellas.

En el sistema de régimen común el Gobierno central recauda en principio los principales impuestos del sistema tributario y posteriormente cede una parte de la recaudación a las CCAA; puede también, en ciertos casos, ceder algunos, como ha ocurrido en España. En el sistema de régimen foral, las Diputaciones, que son las titulares del concierto y convenio, recaudan los impuestos y transfieren una parte al gobierno central, el cupo, que constituye la aportación de estas comunidades para financiar los gastos que el Estado continúa prestando en dichos territorios forales. La diferencia cualitativa es muy importante, pero las repercusiones cuantitativas también lo son; mientras que en las CCAA forales, el $90 \%$ de los ingresos proceden de la recaudación de impuestos, en las de régimen común este porcentaje, a raíz del nuevo sistema, es, por término medio, del $75 \%{ }^{7}$. Hay que destacar que el sistema de régimen común ha avanzado mucho en la autonomía otorgada a las CCAA, ya que hasta el año 2001 el porcentaje de gastos financiado con tributos era, por término medio, del 35\%. Sin embargo, las diferencias entre las CCAA de régimen común también son considerables: por ejemplo, Madrid financia el 100\% de los gastos con ingresos impositivos mientras que Extremadura apenas supera el $35 \%$.

Pero hay algunas cuestiones más concretas sobre la autonomía financiera que conviene todavía destacar:

7 El porcentaje de gasto financiado con ingresos de carácter tributario es una medida (un indicador) de la autonomía financiera. Más ingresos tributarios suponen menos transferencias del Estado y, por tanto, más autonomía.

8 Esto se debe a que en Madrid radican muchas empresas: es allí donde tributan, aunque operan en todo el mercado nacional. 
$1^{\circ}$. En el caso de las CCAA de régimen común se cede capacidad normativa sobre los tributos total o parcialmente cedidos por el Estado. En el caso de las Comunidades forales la figura es distinta: no se trata de tributos cedidos, sino concertados. En el primer caso, el Estado, como titular de los tributos, "cedió" en bloque mediante la Ley 30/1983 la gestión, liquidación y recaudación de algunos de ellos; sólo posteriormente, a partir de 1996, ha ido cediendo capacidad normativa. En el segundo caso, los tributos se conciertan uno a uno, no en bloque; además, no es una cesión, sino un acuerdo entre el gobierno central y las diputaciones forales, mediante el cual se reconoce a estas la gestión de cada tributo ${ }^{9}$.

$2^{\circ}$. Los tributos cedidos a las CCAA de régimen común son el Impuesto sobre Sucesiones y Donaciones, el Impuesto sobre Transmisiones Patrimoniales y Actos Jurídicos Documentados, el Impuestos sobre el Patrimonio, los Tributos sobre el Juego, el Impuesto sobre Matriculación; además, pero sólo parcialmente, el IRPF, el IVA y los Impuestos Especiales. Los tributos concertados con El País Vasco son prácticamente los mismos, pero el rendimiento del IRPF, IVA e Impuestos Especiales que recaudan las Diputaciones, es total; además, el Impuesto sobre Sociedades también es un tributo concertado.

$3^{\circ}$. El gobierno central cede los tributos al gobierno de cada comunidad autónoma de régimen común. En cambio, en el sistema foral, las Diputaciones son las titulares del concierto y por tanto, las que luego transfieren los recursos al gobierno de la comunidad autónoma y a las haciendas municipales vascas.

$4^{\circ}$. En las comunidades forales del País Vasco y Navarra existe un sistema tributario propio ${ }^{10}$, con diferencias incluso dentro de la misma comunidad foral. Esto último se debe a que las Diputaciones son las titulares del concierto y, por tanto, cada una de ellas tiene capacidad normativa propia ${ }^{11}$.

9 Es decir, en las CCAA de régimen común la gestión de los tributos cedidos se efectúa por delegación del Estado, la titularidad del tributo sigue siendo estatal. En las comunidades forales la gestión de los tributos concertados es potestad de los territorios históricos, la titularidad del tributo corresponde a las Diputaciones.

10 La autonomía tributaria del País Vasco es muy amplia, pero debe respetar una serie de principios, entre los que destacan, la solidaridad, la estructura impositiva general del estado, la coordinación y la armonización fiscal.

11 En el concierto vasco se distingue entre tributos concertados de normativa común, es decir, aquellos en los que la normativa viene fijada por la administración central, y tributos 
En las CCAA de régimen común no es posible que existan diferencias dentro de una misma región, ya que el gobierno de la comunidad autónoma es el único titular de la cesión de la capacidad normativa.

Comparando la capacidad normativa de las CCAA de régimen común y foral se observa que, por ejemplo, la de la comunidad autónoma vasca es notablemente superior por las siguientes causas:

1) El número de tributos concertados es mayor que el de los tributos cedidos al resto de comunidades: por ejemplo, estas últimas no tienen cedido el rendimiento del Impuesto sobre Sociedades (además las comunidades forales tienen capacidad normativa sobre este impuesto).

2) La capacidad normativa cedida a las CCAA de régimen común no es plena en ninguno de los tributos cedidos. En el concierto vasco hay tributos de normativa autonómica plena. En el caso del IRPF la cesión del mismo a las CCAA de régimen común es parcial (un 33\%); además, éstas no tienen competencias sobre la gestión de este impuesto, ni siquiera sobre el tramo autonómico, lo cual limita la autonomía financiera que aporta este recurso ${ }^{12}$.

A estas diferencias de principio se añade el hecho de que la aportación de las comunidades forales al Estado se calcula mal y beneficia a estas comunidades dotándolas de más recursos per cápita. Pero, aun prescindiendo de esta circunstancia, es explicable que las diferencias enumeradas induzcan a las CCAA de régimen común a solicitar modificaciones de su sistema de financiación, y que busquen con ello una autonomía financiera similar al foral. Pero lo que se plantea entonces es si esta pretensión es viable cuando se generaliza. $Y$ aquí las conclusiones de diferentes estudios son coincidentes y terminantes: el sistema foral no es generalizable. Las razones son las siguientes:

concertados de normativa autonómica, es decir, sobre los que la comunidad foral tiene capacidad normativa, pudiendo ser esta plena (sobre todos los aspectos del tributo) o no (por ejemplo, sólo sobre la tarifa del tributo). Respecto a la capacidad normativa atribuida a la comunidad autónoma del País Vasco es distinta según el tributo, por ejemplo, es plena en el Impuesto sobre Sociedades, el Impuesto sobre Sucesiones y Donaciones y el Impuesto sobre Transmisiones; en el IRPF es amplia y en el resto es limitada; pero debe ser consistente con la normativa de la Unión Europea.

12 Es curioso que las CCAA han evitado la política impopular de elevar los tipos de los impuestos directos sobre los que tienen capacidad normativa; mientras tanto, algunas lo han hecho con los impuestos indirectos cedidos, cuya carga es menos perceptible para el ciudadano. 
a) algunas CCAA no alcanzarían la suficiencia financiera necesaria para cubrir el coste de las competencias transferidas (por ejemplo, Extremadura);

b) el gobierno central tendría escasez de recursos para financiar las competencias no transferidas a las CCAA, y que, por lo tanto, seguiría prestando este nivel de gobierno.

Además, las CCAA que más ganarían son las de mayor desarrollo socioeconómico.

No obstante, este planteamiento no convence a algunos miembros del gobierno catalán, los cuales proponen, no que el sistema foral se generalice a todas las CCAA de régimen común, sino que se le aplique a Cataluña. Concretamente esta aspiración es de Esquerra Republicana de Cataluña (ERC); el Partido Socialista Catalân (PSC) propone aportar según renta y percibir según población. Pero ambas propuestas encierran dificultades de cierto peso.

\section{Las propuestas para aproximar ambos regímenes: errores técnicos y valores en juego}

El conjunto de propuestas planteadas por el gobierno catalán y, en menor medida, por el andaluz tienen como finalidad aumentar la autonomía financiera de las CCAA de régimen común; lo que buscan es, en definitiva, aproximar el régimen de financiación común al foral, como expresamente lo ha formulado ERC. No obstante, también hay otras razones económicas implícitas: estas dos comunidades están en el grupo de las que tienen un ratio de deuda sobre el PIB mayor, lo que explica que vean en una mayor autonomía financiera la vía para generar recursos que les permitan atender el pago de la deuda.

Entre las propuestas existen cuestiones formales que afectan a la negociación del sistema, como la intención de Cataluña de negociar bilateralmente con el gobierno central su sistema de financiación; otras propuestas son de carácter técnico, aunque también conllevan implícitamente cuestionamientos políticos y económicos, como la creación de agencias tributarias autonómicas y los criterios de reparto del gasto estatal; además la argumentación de Cataluña gira en torno al saldo de la balanza fiscal, de lo que también nos ocuparemos.

Hemos agrupado las distintas cuestiones en debate en cinco preguntas. Que- 
remos aportar algo de luz sobre errores técnicos que se cometen en algunas de ellas, pero sobre todo deseamos poner de manifiesto los principios que se cuestionan en otras.

a) El sistema de financiación autonómica que se aprobó en 2001, ¿está abierto a una nueva negociación, o se puede considerar un sistema definitivo?

b) La financiación de las CCAA de régimen común ¿se debe negociar bilateralmente entre el Estado y cada comunidad o es preferible hacerlo a través de una negociación común?

c) El saldo de la balanza fiscal ¿mide la solidaridad?

d) ¿Qué ventajas e inconvenientes tendría la creación de agencias tributarias autonómicas?

e) ¿Cuáles deben ser los criterios de distribución de los gastos públicos?

4.1. ¿Puede considerarse definitivo el sistema de financiación autonómica que se aprobó en 2001?

Cuando se aprobó el último sistema de financiación se le otorgó un carácter indefinido: prueba de ello es que fuera aprobado por ley. Sin embargo, algunos gobiernos autonómicos han propuesto reformas o modificaciones del mismo. ¿Qué razones justificaron en el año 2001 que se otorgara a dicho sistema un carácter indefinido? ¿Qué argumentos invocan las comunidades que propugnan su reforma?

La razón principal para que se otorgara al sistema de 2001 un carácter indefinido es que con él estaba previsto finalizar el proceso de traspaso de competencias a las CCAA. Por otra parte, este nuevo sistema respondía a las principales demandas autonómicas sobre financiación e integraba en un solo sistema la financiación de todas las competencias transferidas (comunes, sanidad y servicios sociales de la SeguridadSocial). Todas ellas se consideraron razones suficientes para dar estabilidad al sistema. A lo anterior hay que añadir que el acuerdo fue alcanzado en el seno del Consejo de Política Fiscal y Financiera $(\mathrm{CPFF})^{13}$, en el que están representados los gobiernos de todas las CCAA: y no puede decirse que se trató sólo de un acuerdo entre PP y PSOE, porque, en ese momento, era Convergencia i Unió (CiU) quien gobernaba en Cataluña.

13 La LOFCA (1980) recoge la creación del CPFF como órgano encargado de coordinar la actividad financiera de las CCAA y de la Hacienda estatal. 
Que el sistema tenga una vigencia indefinida no quiere decir que no pueda ser reformado. El Estado de las autonomías es una realidad cambiante $y$, por tanto, su sistema de financiación también debe serlo. Pero ¿tan pronto? ¿Qué ha cambiado en estos dos años (desde 2002 se está aplicando el nuevo sistema) que justifique un cambio del mismo? ¿Bastan los últimos cambios de gobierno en Cataluña $y$, más recientemente, en España?

En realidad han sido Cataluña y Andalucía las que ya han considerado que se puede provocar un nuevo avance en la autonomía de las regiones, por ejemplo, mediante la creación de Agencias Tributarias Autonómicas o equiparando la autonomía de las CCAA de régimen general a la de las comunidades forales.

Por otra parte, hay quienes consideran que el sistema debe revisarse, como hasta ahora, cada cinco años. Pero esta razón no nos parece de mucha consistencia, ya que ni la LOFCA, ni, por supuesto, la Constitución, establecen una revisión periódica del sistema de financiación autonómico. La razón por la que efectivamente, y hasta 2001, el sistema ha sido objeto de revisión quinquenal es que así se preveía para la modificación de la participación en los ingresos del Estado (PIE), que ha sido el principal instrumento de la financiación autonómica durante mucho tiempo. Aunque en teoría el único instrumento que debía revisarse era la PIE, en la práctica era revisado el sistema en general, otorgándosele al acuerdo una vigencia quinquenal. Esta vigencia temporal otorgada estaba justificada en la medida en el sistema de financiación autonómica estaba todavía en formación, en desarrollo, como las mismas CCAA hasta 2001.

4.2. El sistema de negociación para las comunidades de régimen común ¿debe ser bilateral o común?

La negociación bilateral de la financiación autonómica ha sido planteada por Cataluña. Tal propuesta supone que esta comunidad se saldría del sistema LOFCA y de la negociación de un sistema de financiación común en el seno del CPFF. Formalmente, la financiación autonómica de Cataluña quedaría recogida en su Estatuto de autonomía, y no en la LOFCA.

Es cierto que un mismo modelo de financiación autonómica no satisface por igual a todas las CCAA, ya que sus realidades socioeconómicas son diferentes. Aun así, desde nuestro punto de vista, un único sistema es preferible a tantos sistemas como comunidades hay. Un Estado autonómico en el que cada región tuviera un sistema de financiación diferente difícilmente tendría estabilidad 
financiera, pues cualquierregión estaría permanentemente tentada a compararse con el resto y a proponer modificaciones de su modelo de financiación.

La existencia de un mismo sistema de financiación regional también se puede argumentar constitucionalmente ${ }^{14}$. Los sistemas de financiación de las CCAA deben ser sólo los cuatro que tienen una base constitucional (el foral, el de régimen común, el hecho insular y el caso de Ceuta y Melilla). Sólo se justificarían particularidades en la financiación en el caso de CCAA con competencias distintas, como ha sido el caso de aquellas que tenían transferidas las competencias en materia sanitaria. Salvo en estas situaciones, las CCAA deben adoptar un sistema común, ya que mantienen la misma posición constitucional.

Si la posición constitucional de Cataluña es idéntica a la de otras CCAA de régimen común, ¿qué justifica su exclusión del sistema LOFCA? ¿por qué su financiación va a ser acordada bilateralmente con el Estado, sin contar con el resto de comunidades autónomas? El argumento que esgrime Cataluña es, de nuevo, el saldo de la balanza fiscal, cuestión que analizaremos en el apartado siguiente.

Todavía hay que aludir a otra circunstancia que desaconsejaría la multiplicación de sistemas de financiación autonómica. Porque existe un límite a cualquier cesión de capacidad normativa y administrativa de la Administración Central a las CCAA, que tiene que ver con nuestra integración en la Unión Europea: las necesidades de armonización fiscal y los compromisos de financiación de las instituciones europeas. La armonización fiscal se hace tanto más necesaria cuanto más se avanza en el proceso de integración económica y monetaria: en ese marco no es concebible una cesión de capacidad normativa que pueda suponer una clara competencia fiscal. La derogación por parte del Tribunal Europeo de la normativa de vacaciones fiscales para las empresas radicadas en el País Vasco así lo corrobora. Tampoco es posible descentralizar tanto el sistema que fueran las CCAA las encargadas de pagar el cupo a la Unión, puesto que esa es una obligación de los Estados miembros. En suma, el proceso de integración europea -que afecta también al sistema fiscal, aunque el avance sea lento en este campo, como ocurre con todas las políticas de calado en la Unión Europea-marca un límite inexorable a este proceso de descentralización fiscal en España.

14 J. García, P. PÉRez. y J. Zornoza, (1998), Constitución y financiación autonómica alternativa, Valencia, Tirant lo Blanch, pp. 189. 
4.3. ¿Es el saldo de la balanza fiscal un buen indicador de la solidaridad?

En la argumentación referente al saldo de la balanza fiscal, que ha empleado el tripartito catalán, se ha aludido con frecuencia a los Länder alemanes para justificar un límite al déficit de dicha balanza: y es que una sentencia del Tribunal Constitucional alemán fijó un límite a este déficit. Pero el sistema de solidaridad regional alemán no es comparable con el español. Veamos por qué.

Comencemos analizando por qué el saldo de la balanza fiscal no es un indicador de la solidaridad interregional. En este análisis no entraremos en las dificultades técnicas de cálculo de dichas balanzas; nos basta dejar constancia de que son distintos los criterios que se pueden aplicar para la imputación de ingresos y gastos a las regiones.

Una primera cuestión, y tal vez la principal, es que los impuestos los pagan las personas, no los territorios. Como el sistema fiscal es progresivo-aunque, desgraciadamente, lo sea cada vez menos-, resulta que en las regiones con mayor concentración de rentas se recaudan más impuestos. Pero esto es una consecuencia directa de la progresividad del sistema fiscal, según la cual los impuestos se pagan en función de la renta y del uso que se hace de ella, no en función de la identidad de origen del contribuyente. Además, adviértase que el andaluz que tributa en el tramo más alto de renta está en la misma posición ante hacienda que el madrileño o el catalán que tributan en el mismo tramo: no se podría justificar, entonces, que el nivel de prestación de los servicios públicos que recibiera no fuera el mismo.

Por otra parte, no todo lo que el Estado recauda en una región lo pagan los residentes de dicha región (porque una parte de la base imponible se genera fuera de ese territorio). Además, cuando el Estado cede el 33\% del IRPF a Madrid, por ejemplo, está renunciando a una cantidad mayor de recursos que cuando cede ese mismo 33\% a Extremadura.

Junto a esas razones de carácter fiscal, hay otras de índole diferente. La más importante es que en el cálculo de los beneficios y costes hay que incluir también los beneficios económicos que supone acceder al mercado nacional. Entonces resulta que, junto a una balanza fiscal deficitaria, Cataluña tiene una balanza comercial excedentaria, cosa que repercute muy favorablemente sobre el empleo y la riqueza de dicha región ${ }^{15}$.

15 También habría que computar la cuenta financiera que forma parte de la balanza de pagos. Pero este es un aspecto que se aparta sustancialmente del tema de este editorial. 
Y por último hay aquí una cuestión de carácter ético: la justicia distributiva. En ella se basa todo el Estado social, que busca distribuir las cargas y los beneficios que genera la convivencia social, no de forma proporcional, sino según las capacidades y las necesidades de cada uno. La distribución del gasto estatal según el criterio exclusivo de población, como ha propuesto alguna comunidad, supone renunciar a este modelo de Estado y a los valores por los que en él se apuesta.

Por otra parte, tampoco creemos que se pueda invocar aquí la experiencia de los Länder alemanes, como expondremos a continuación.

La instrumentación del principio de solidaridad puede llevarse a cabo de dos formas: a) mediante la existencia de flujos financieros entre las regiones a través de un fondo de suma cero (solidaridad horizontal), y b) mediante transferencias de recursos del gobierno central o federal a los gobiernos regionales (solidaridad vertical). El sistema alemán responde al primer tipo, mientras que el español corresponde al segundo: por eso no son comparables.

El sistema alemán es complejo, ya que posee hasta tres mecanismos diferentes de nivelación:

a) El IVA. De su recaudación, el 75 por ciento se reparte entre los Länder en función de la población y el 25 por 100 se destina a aproximar los recursos de los Länder al 92 por 100 de la media de los recursos per cápita de los mismos.

b) Un fondo de suma cero. Su finalidad es que todos los Länder alcancen como mínimo un 95 por 100 de los recursos medios totales. Las aportaciones a dicho fondo se efectúan tomando como valor 100 la media de los recursos totales. Cada Land aporta al fondo el exceso sobre 100 según estas reglas: los dos primeros puntos sobre 100 no se aportan; entre 102 y 110, se aporta el 70 por 100 de lo que corresponda; los recursos que excedan en más de diez puntos se aportan en su totalidad.

c) Una subvención de la Federación a los Länder menos ricos.

Como resultado del mecanismo descrito en el apartado b) unos Länder son aportantes netos y otros receptores netos. El Tribunal Constitucional alemán ha limitado la aportación que hacían los Länder más ricos, pero obsérvese que la aportación se realiza de los recursos de la financiación total que obtiene cada Land, y no de la recaudación que el gobierno federal obtiene de los ciudadanos de la región. 
En el sistema de financiación de las CCAA españolas, la solidaridad está implícita en las variables de reparto de los distintos fondos con que se financian las competencias transferidas, y es explícita en los recursos que perciben del Fondo de Compensación Interterritorial, cuyo fin es reducir las desigualdades interregionales, así como en las asignaciones de nivelación, cuyo fin es nivelar el acceso a los servicios públicos de los ciudadanos de cada región.

El principal problema estriba en cómo conciliar los principios de autonomía financiera y solidaridad, y ese problema es común a todos los Estados, tanto a los federales como a los unitarios, porque en todos ellos los derechos a unas prestaciones públicas son iguales para todos sus ciudadanos, independientemente del nivel de renta de la región en que habiten. La diferente capacidad financiera de cada región puede dar lugar a que una comunidad autónoma, realizando el mismo esfuerzo fiscal que otras, pueda tener mayores ingresos impositivos per cápita $y$, por tanto, un mayor nivel en la prestación de los servicios públicos. Como ya dijimos más arriba, no puede haber autonomía sin solidaridad porque eso llevaría al incumplimiento de otro principio, el de igualdad en el nivel de acceso y prestación de los servicios públicos de los ciudadanos en todo el territorio nacional.

La solidaridad está presente en los países federales, pero no en todos con la misma intensidad. En Estados Unidos y Suiza la nivelación de recursos es escasa. En el otro extremo se encuentran Alemania, Australia o Canadá, en los que la nivelación es elevada, sin que en ninguno de ellos se llegue a alcanzar la igualdad de recursos per cápita. ¿A quién queremos parecernos? ¿cuál es nuestra escala de valores como Estado?

No ignoramos que las propuestas de reforma de la financiación autonómica que estamos discutiendo no se olvidan totalmente de la solidaridad. Pero vinculan la solidaridad interregional al saldo de la balanza fiscal de cada región. Esto es lo que nos parece inaceptable. Concretamente, el gobierno catalán propuso fijar un fondo de solidaridad con el resto de comunidades para que todas alcanzasen un nivel similar de prestación de los servicios a igual esfuerzo fiscal, pero este fondo requería la publicación previa de las balanzas fiscales. ¿Qué quiere decir esto? ¿que su aportación al fondo estaría en función del saldo de la balanza fiscal? ¿Qué solidaridad es esa si la solidaridad es redistribuir recursos a favor de los que tienen un nivel de desarrollo menor? Tampoco se les pide que hagan esto de una forma absolutamente desinteresada: ¿o no es cierto que el desarrollo de las regiones más desfavorecidas termina favoreciendo a las más desarrolladas? 
Admitamos que se propongan reformas de la financiación autonómica. Pero no se argumenten con el saldo de la balanza fiscal. El único argumento con cierta validez aquí sería el de buscar vías para una mayor aproximación de la autonomía del sistema general al foral. Pero esta búsqueda no habría que circunscribirla a la reforma del sistema general: a lo mejor habría que reformar también el régimen foral...

4.4. ¿Qué ventajas e inconvenientes tendría la creación de agencias tributarias autonómicas?

Toda Administración tributaria debe tener básicamente dos características: recaudar de una manera eficiente y luchar contra el fraude fiscal. Pues bien, es muy posible que el cumplimiento de ambas se vea dificultado con la multiplicación de agencias tributarias. Veamos.

La proliferación de un gran número de agencias tributarias de ámbito autonómico probablemente dificultará la lucha contra el fraude fiscal porque el nivel de información con que contarían estas múltiples agencias tributarias se reduciría, al quedar limitado básicamente a los actos, operaciones o transacciones -hechos imponibles, en general-de incidencia en los tributos que gestiona y recauda esa comunidad autónoma. De esta forma resulta indudable que se dificulta el control cruzado de operaciones. Este control se puede realizar con mayor facilidad cuando se dispone de la información que proporcionan los operadores económicos que actúan en la mayor parte del territorio español.

Aunque en la actualidad las CCAA gestionan y recaudan algunos tributos, se trata fundamentalmente de impuestos de carácter esporádico (técnicamente denominados impuestos instantáneos), como son el Impuesto sobre Sucesiones y Donaciones, el Impuesto sobre Transmisiones Patrimoniales y Actos Jurídicos Documentados, etc. También gestionan algunos otros de carácter periódico (Impuesto sobre el Patrimonio, etc.), pero no es en estos donde se producen importantes "tramas" de fraude. Las tramas de fraude más significativas se dan en impuestos como el IVA, el Impuesto sobre Sociedades, el IRPF (en lo concerniente a las rentas empresariales o profesionales), etc. Y en estos casos su descubrimiento pasa necesariamente por el cruce de datos de distintos proveedores, clientes, etc. Si bien es cierto que se podrían establecer sistemas de coordinación e información entre agencias tributarias, esto no es fácil de articular en la práctica (piénsese como ejemplo en las dificultades que plantea el control de las operaciones intracomunitarias en el IVA). En todo caso, eso implicaría 
unos mayores costes: los derivados de todo proceso de coordinación.

Desde esta perspectiva, resulta paradójico que en otros ámbitos se esté apostando por un mando único (para la investigación de delitos), del que dependería el Cuerpo Nacional de Policía y la Guardia Civil, en aras de una mayor eficacia, mientras que en el ámbito fiscal se está optando por la descentralización. En temas como la investigación o descubrimiento de hechos ocultos suele ser una opción técnicamente más ventajosa la concentración de información y el tratamiento de la misma de una forma centralizada.

Tampoco resulta descabellado pensar que la lucha contra el fraude, sobre todo el que afecta a determinados sectores económicos, se puede ver dificultada por la influencia de determinado grupos de presión, que en ámbitos de decisión política más reducida ven incrementado su poder de influencia. Sobre todo en cuestiones dudosas o de no fácil solución técnica, podrían tener más influencia de la deseada ciertos criterios de decisión política.

También es muy probable que se incrementen los costes de recaudar los tributos. No sólo no se podrá prescindir del todo de una agencia de ámbito estatal, sino que habría que crear múltiples estructuras descentralizadas, lo que incrementaría los costes de estructura y eliminaría las ventajas de las economías de escala. Esta variable no es desdeñable dado el carácter netamente instrumental que tiene la recaudación tributaria. Si bien parece razonable que cada comunidad autónoma quiera prestar determinados servicios a sus ciudadanos -y de ahí la transferencia de competencias en servicios esenciales, como son la educación, la sanidad, la cultura, etc.-, resulta discutible que esta razón valga igualmente cuando se trata de servicios instrumentales. Garantizado un procedimiento adecuado para la recaudación tributaria -y no creemos que haya mucho margen para prestarlo de forma muy dispar-, lo lógico es reducir sus costes. De no ser así, habría que aumentar la presión fiscal para mantener la recaudación neta.

Es probable además que se incremente la presión fiscal indirecta sobre los operadores económicos que actúan en todo el territorio nacional, los cuales tendrán que relacionarse con múltiples agencias tributarias. Incluso puede ocurrir que las agencias tributarias, ante las dificultades que puedan encontrar a la hora de contar con información que le permita realizar controles cruzados, soliciten a los operadores económicos información que ya han suministrado a otras agencias tributarias. 
Hay que valorar también el contexto de una economía abierta y global, en que todo esto ineludiblemente se va a tener que realizar. Gestionar el sistema tributario de forma tan "regionalizada" dificultará el control de operaciones, impondrá importantes esfuerzos de coordinación a las distintas administraciones públicas, exigirá a los ciudadanos un perfecto conocimiento de sus obligaciones tributarias para con cada una de las múltiples administraciones implicadas. En definitiva, en un mundo cada vez más global no parece que esta "territorialización" contribuya a la eficacia y a la eficiencia del sistema tributario.

La multiplicación de agencias tributarias dificultará también la política económica. La recaudación excesivamente territorializada podría dificultar la intervención del Estado en la economía a través de la vertiente del gasto, pues este no podría disponer de tantos recursos, siquiera de forma transitoria, como ocurre ahora. Todo esto es más grave aún si se tienen en cuenta las restricciones que impone el compromiso de la estabilidad presupuestaria y la transferencia de toda la política monetaria al Banco Central Europeo.

¿Y no resulta paradójico que sean fundamentalmente los partidos vinculados a la izquierda política los que protagonizan esta propuesta? Precisamente son ellos los que han exigido de forma más contundente la lucha contra el fraude fiscal organizado y la intervención del Estado en la economía.

La propuesta de creación de agencias tributarias autonómicas contrasta también con la opinión de los expertos recogida en el Libro Blanco de la financiación autonómica ${ }^{16}$. Lo que ellos proponían era la creación de una Agencia Tributaria Integrada (ATI), una agencia independiente que se encargaría de la administración de los tributos compartidos entre las haciendas autonómicas y central. Tal y como indicaban los autores del Libro Blanco, no se trataría de que la hacienda central pasara a administrar los tributos de las CCAA, sino que la hacienda central y las haciendas autonómicas fueran administradas por una misma organización independiente, pero en la que ambas pueden participar $y$ tomar decisiones.

Los autores del Libro Blanco identificaban dos inconvenientes para que la actual Agencia Estatal de la Administración Tributaria (AEAT) fuera la base de la ATI: su falta de autonomía política (depende de la Administración central) y la presencia de rigideces laborales (por ejemplo, la imposibilidad del despido del personal). Ambas afectarían a su eficacia. Probablemente el

16 VARIOS, (1995), Informe sobre el actual sistema de financiación autonómica y sus problemas, Madrid, Instituto de Estudios Fiscales, pp. 290. 
principal obstáculo para la creación de una Agencia Tributaria Independiente es el deseo de la Administración central de no perder el control sobre los principales impuestos del sistema tributario. Sin embargo, tal vez su creación hubiera evitado propuestas como la catalana.

Pero no siempre los expertos coinciden. Un estudio más reciente ${ }^{17}$ concluye que el gobierno central no ha prestado la suficiente atención a la gestión de los tributos cuyo rendimiento se ha cedido, total o parcialmente, a las CCAA. De hecho -dicen- la AEAT ha centrado sus esfuerzos en la gestión del Impuesto sobre Sociedades y el IVA. De ahí que los resultados de la lucha contra el fraude empeoraran en el periodo comprendido entre 1997 y 2001. Según los autores de dicho trabajo, la creación de agencias tributarias autonómicas mejoraría la gestión de los tributos. Pero -añadiríamos nosotros- ¿no podría ser la ATI una buena solución, precisamente por ser un organismo independiente de los distintos niveles de gobierno, que no tendría más interés por la gestión de unos tributos que por la de otros?

Terminamos este apartado con una referencia a la experiencia comparada. En Alemania los Länder tienen un sistema de financiación basado en participaciones territorializadas en un único sistema impositivo: en él los principales impuestos son de normativa federal, pero los impuestos compartidos son administrados por los Länder por delegación del gobierno central.

4.5. ¿Cuáles deben ser los criterios de distribución de los gastos públicos?

También se incluyen, entre las propuestas de modificación del sistema de financiación autonómica, algunas que afectan a la distribución de los gastos públicos. En esta cuestión hemos de distinguir entre gasto corriente (el orientado a generar la prestación de un servicio público) y gasto de capital (el derivado de nuevas inversiones). Cataluña propuso que el primero fuera proporcional a la población, y el segundo al PIB de la región. Analicemos por separado ambas cuestiones.

Respecto a los gastos corrientes, en el nuevo sistema hay tres fondos para financiar los distintos bloques de competencias transferidas a las CCAA (competencias comunes, sanidad, servicios sociales de la Seguridad Social). Los criterios de reparto son diferentes en cada bloque.

17 Realizado por Jesús Ruiz-Huertas y Octavio Granado, que será publicado en el Informe anual sobre CCAA, del Instituto de Derecho Público de Barcelona. 
Centrémonos, por ejemplo, en el bloque de competencias comunes. Actualmente, el peso de la variable población es del 94\%. Pero se incluyen, además, otras variables que se considera afectan al coste de prestación de dichos servicios públicos: en concreto, la superficie (4,2\%), la dispersión de la población (1,2\%) y la insularidad $(0,6 \%)$. La financiación de estos servicios se completa con un fondo que compensa a las CCAA con menor renta, y con otro que compensa a las CCAA con menor densidad de población.

La selección y ponderación de estas variables no responde a un estudio económico: deriva de un acuerdo en el que cada comunidad autónoma trata de defender aquella variable o variables que más le benefician. ¿Se podría decidir, como pretende Cataluña, que sea la población el único criterio de distribución? En teoría sí, y de hecho es la principal variable de la que depende el coste. Pero no es la única, y por eso algunas CCAA no están dispuestas a renunciar a otras, a lo que tienen pleno derecho. ¿Se podrían fijar unas variables diferentes para cada comunidad? Eso ya sería casi como definir un sistema de financiación diferente para cada comunidad, tema sobre el que ya nos hemos pronunciado más arriba.

El criterio propuesto para la asignación de los gastos de capital es más cuestionable todavía. Por una parte, ignoraría el principio de la redistribución: asignar a Cataluña, que tiene el 16\% de la población nacional, un 19\% del total de la inversión nacional (que es el peso relativo del PIB de esta región), significaría actuarpara que su renta percápita creciera más rápidamente. ¿Cómo compaginar eso con una política redistributiva, y precisamente en los gastos de inversión, que es donde los efectos redistributivos pueden ser más eficaces? Pero es que, además, la teoría económica indica que la inversión en infraestructuras ha de hacerse donde sea mayor su beneficio, es decir, allí donde la diferencia entre el aumento previsible de la renta y el coste de la infraestructura sea mayor. A esta conclusión se llega aplicando algo tan elemental en teoría económica como es la ley de los rendimientos decrecientes. ¿No sería como afirmar que es mejor construir una tercera autovía entre Marbella y Sotogrande que una primera entre Antequera y Lucena, aduciendo que las dos primeras ciudades tienen una renta más alta que las segundas? 


\section{Consideraciones finales}

La discriminación que establece el sistema foral de financiación respecto al sistema de régimen común es la razón última por la que la financiación autonómica sigue siendo objeto de reformas. En esta ocasión, como en otras anteriores, las propuestas más elaboradas han surgido en Cataluña. Parece existir una correlación positiva entre sentimientos nacionalistas y autonomía financiera. Esta relación no es de extrañar, ya que es precisamente el dinero, la autonomía financiera, el que permite el ejercicio de la autonomía política y la puesta en práctica de la decisiones derivadas de esta. ¿Es que Cataluña ha visto claro desde el principio que el camino a una mayor autonomía política implica más autonomía financiera? La pretensión de una agencia tributaria catalana es muy coherente con este planteamiento.

Junto a esa lectura política de las propuestas catalanas caben otras. Porque hay otras CCAA que, en este u otros momentos, han propuesto reformas de la financiación autonómica. Son, porejemplo, Valencia (1996) o Andalucía(2004), precisamente las más endeudadas. También Cataluña debe incluirse en este grupo. ¿Tiene que ver la reivindicación de estas reformas con la necesidad de buscar salida al problema del endeudamiento?

Estas y otras posibles interpretaciones de los motivos que llevan a las CCAA a proponer reformas del sistema de financiación invitan a pensar que el debate sobre las mismas no puede ser obviado. Pues bien, de cara a entrar en él se nos ocurre formular algunas conclusiones como resultado de este artículo editorial:

- La existencia de dos regímenes de financiación autonómica diferentes en España es fuente de problemas, pero es ineludible: no sólo tiene un origen histórico, sino que además cuenta con el respaldo de la Constitución.

- Generalizar el sistema de financiación foral al resto de CCAA no sería financieramente posible, ya que el gobierno central tendría insuficiencia de recursos y algunas comunidades también.

- Que una comunidad autónoma concreta, de régimen común, aspire a un sistema de financiación similar al foral, es comprensible, dada la discriminación que establece el sistema foral; pero no está justificado con la actual Constitución en la mano. Es más, dado que ese sistema foral no es generalizable, tal actitud podría parecer falta de una suficiente solidaridad. 
- La financiación autonómica debe evolucionar de tal forma que ambos sistemas vigentes se aproximen, cuantitativa y cualitativamente, en cuanto al grado de autonomía que permiten. De hecho, la evolución reciente ha ido por ese camino. Pero este avance debe beneficiar a todas las CCAA de régimen común, de forma que no se sacrifique la solidaridad, en su doble vertiente interpersonal e interterritorial. La igualdad o equidad es un derecho constitucional.

- A la hora de establecer mecanismos de descentralización fiscal no podemos ignorar nuestra pertenencia a la Unión Europea y las exigencias de armonización fiscal que de ahí derivan.

- Cuando se habla de financiación autonómica se suele olvidar que una de las figuras tributarias de mayor eficacia recaudatoria son las cotizaciones sociales. Además, el gasto social que se financia con ellas, no sólo es uno de los que aporta más réditos políticos, sino que tiene un profundo valor en términos de solidaridad intergeneracional. Por otra parte, el sistema de Seguridad Social (como cualquier sistema de seguros) es más viable cuanto más amplia sea la población que suscribe el riesgo, de forma que fragmentarlo podría llevar a que algunas CCAA con poco crecimiento poblacional y fuerte emigración pasada se colapsara en pocos años. ¿No es llamativo, a este respecto, que el País Vasco haya rebajado el tono de la petición de las transferencias de la Seguridad Social (aunque lo contempla el Plan Ibarretxe)?

- El Estado español debe seguir avanzando en el proceso de descentralización del gasto y del ingreso. Pero ahora el reto principal lo tienen ante sí las CCAA: en virtud del Pacto Local, es a ellas a quienes toca en este momento ceder parte de las competencias a los gobiernos locales.

Todo proceso de negociación-como ocurre con el relativo a un acuerdo estatal sobre la financiación autonómica-exige que se asuman ciertos compromisos que doten de estabilidad a sus resultados (en nuestro caso, a la estructura financiera acordada). Pero esta estabilidad es imposible si el modelo de Estado español se pone en entredicho a partir de cada acontecimiento electoral a nivel estatal o autonómico. Sin embargo, resulta muy difícil que la visión del Estado sirva de freno a propuestas de mayor autonomía de las CCAA: porque los partidos nacionalistas fundamentan gran parte de su identidad en la consecución de cuotas de soberanía y autogobierno, y los partidos nacionales pagarían un alto coste electoral si ignorasen estas reivindicaciones. La paulatina configuración del Estado español como un estado federal asimétrico ¿no está requiriendo un 
gran pacto entre partidos, con la Constitución como referente, que proteja a este tema frente a una cierta instrumentalización electoralista? Hay precedentes significativos en nuestra historia política reciente, como son el Pacto de Toledo o el de la Lucha Antiterrorista. ¿No son ambos un exponente de madurez política y la prueba más terminante de que cabe llegar a acuerdos que están más allá de los intereses partidistas y de la utilización de ciertos símbolos como arma electoral? Posturas como estas no impiden la reforma, ni de nuestra Carta Magna ni de los Estatutos de Autonomía. Pero ambas cosas habría que abordarlas, huyendo de todo oportunismo electoral, como verdaderas cuestiones de Estado y con el rigor que tales temas exigen. 